\title{
ERROR MANAGEMENT
}

\section{Quantifying distraction and interruption in urological surgery}

\section{A N Healey, C P Primus, M Koutantii}

See end of article for authors' affiliations

.....................

Correspondence to:

Dr A N Healey, Department

of Biosurgery and Surgical

Technology, Clinical Safety

Research Unit, Imperial

College, University of

London, 10th Floor QEQM

St Mary's Hospital, Praed

Street, Paddington, London

W2 INY, UK; a.healey@

imperial.ac.uk

Accepted 27 January 2007
Qual Saf Health Care 2007;16:135-139. doi: 10.1136/qshc.2006.019711

Background: To enhance safety in surgery, it is necessary to develop a variety of tools for measuring and evaluating the system of work. One important consideration for safety in any high-risk work is the frequency and effect of distraction and interruption.

Aim: To quantify distraction and interruption to the sterile surgical team in urology.

Methods: Observation of the behaviour of the surgical team and their task activity determined distraction and interruption recorded. Using an ordinal scale, an observer rated each salient distraction or interruption observed in relation to the team's involvement.

Results: The frequency of events and their attached ratings were high, deriving from varying degrees of equipment, procedure and environment problems, telephones, bleepers and conversations.

Discussion: With further refinement and testing, this method may be useful for distinguishing ordinal levels of work interference in surgery and helpful in raising awareness of its origin for postoperative surgical team debriefing.
$\mathrm{S}$ urgical skill and patient-specific conditions together determine the outcome of surgery. However, focusing only on these determinants assumes that surgeons and other professionals in surgery will perform highly and uniformly, regardless of the variable conditions of their work. ${ }^{1}$ A systems view recognises that professional skills alone are not sufficient to determine outcome because the operation of the system involves many interdependent variables, some of which are not necessarily under one's control. ${ }^{2-4}$ Workload, the reliability and effectiveness of equipment, and the conditions of the operating theatre environment may all affect anaesthetic, ${ }^{5}$ nursing and surgical performance. ${ }^{67}$ The implication of this argument is that to improve the reliability of surgery, there must be a preoccupation with identifying and rectifying variation within the system that is potentially detrimental to performance. ${ }^{8}$ This is consistent with the general approach to safety adopted in other high-risk domains.

Critical incident reporting methods provide a valuable means by which to monitor the causes of near misses or adverse events retrospectively. They give some indication of the problems experienced by operating theatre staff, such as equipment problems, which may contribute to $4 \%$ of all hospital incidents reported. ${ }^{10}$ One study, for example, showed that over an 11 -year period from 1000 anaesthetic critical incident reports at a Leicester hospital there were 395 anaesthetic incidents involving equipment problems. ${ }^{11}$ However, reports rely on variable efforts in reporting for fear of blame, and with retrospective research it is difficult to attribute cause to events ${ }^{12}$ as they often have a background of complexity, in terms of latent failure. ${ }^{13}$

Research must address the broader conditions of work which may contribute to system failure. Of particular concern are distractions and work interruptions because of their possible contribution to excessive workload and task performance. ${ }^{14}$ Observational measures are therefore useful means by which to conduct prospective research for evaluating the causes of work distraction and interruption ${ }^{15}{ }^{16}$; they provide an alternative to, and complement, reporting systems. ${ }^{17}$ Results from observational studies suggest that distraction or interruption indeed compromise performance in the operating theatre. ${ }^{18} 19$ One approach has been to try to quantify distraction and interruption observed in the operating theatre in an attempt to measure the overall work interference in surgery. ${ }^{20}$ Broadly speaking, the assumption with this approach is that the unhindered flow of surgical processes reflects a system performing effectively, whereas distraction or interruption reflects interference within the system. A rate of one observed distraction or interruption every 3 min was recorded in general surgery using this method; a similar frequency of interruption was found in an emergency department. ${ }^{21}$ Results showed reasonably high reliability for the rating of individual distractions and interruptions and for aggregate scores assigned to operations. This article reports a similar method applied to urological surgery, where the unit of analysis was the sterile surgical team and their circulating support staff, rather than the entire operating theatre personnel. This difference served to reduce the scope of the system assessed and to increase observer focus. We also measured interruption duration. This study had the following aims relating to urological surgery in a single operating theatre:

(1) to measure the frequency of distraction and interruption in a single sample;

(2) to identify the source of distraction and interruption in the sample;

(3) to evaluate noise in the operating theatre with sound pressure measurement.

\section{METHODS}

\section{Sample}

The sample included 30 urology day-case procedures (see Results section for details) collected over a 2-month period from the operating lists of four consultant urologists practising in a single operating theatre of a central London teaching hospital. The relevant ethics committee approved the research before observations began. Data collection demanded sustained, high-level concentration. Therefore, to maintain the quality of the data collected, the researcher observed day-case procedures of (predicted) relatively short duration. Sampling started from the formation of the sterile field and ended with deconstruction of the sterile field, representing the intraoperative phase of surgery. ${ }^{22}$ 


\section{Measures}

An observer recorded events that distracted or interrupted the sterile surgical team. We defined distraction as observed behaviour such as orienting away from a primary task or verbally responding to a secondary task. We defined interruption as a distraction resulting in a break in primary task activity. We constructed a rating scale to reflect ordinal levels of team involvement in an event of a distracting or interrupting nature (table 1). Scale point 1 refers to events with the potential to distract the sterile team. Scale point 2 refers to similar events noticed by the staff supporting the sterile team. Scale points 3-5 reflect the possible involvement of a single sterile team member in an event not related to their current work. If they responded to a visual or auditory stimulus with a short head turn, for example, this would rate 3 . If they were similarly distracted, but then engaged in the source of distraction by verbally responding while maintaining primary task activity (ie, multitasking), this would rate 4 . If the single team member ceased their current tasks to engage entirely on the distraction, this would become an interruption and correspond to point 5 on the scale. Scale points $6-8$ are similar to points $3-5$, but involve two or more members of the sterile team. Point 8 refers to noticeable disruption to the whole surgical team's work. Thus, the scale relates to the level of impact on the sterile team. The two lower levels relate to events that might encroach on the sterile team where support staff notice or deal with the distraction. The following levels relate to the level of sterile team engagement in an event, from distraction to interruption at the individual level or at the team level. The observer recorded a brief description of each distraction or interruption and rated each using the ordinal scale, also noting the time of onset and end of observed work interruption. Concurrently, the observer collected a tally of personnel entering or leaving the operating theatre.

\section{Materials}

The observer used a standardised data record form in table format with separate columns to insert data on predefined variables. The observational data were entered into the following categories: case-irrelevant conversation, telephone calls, bleepers, equipment, procedure, work environment and movement behind the endoscopic/fluoroscopic displays. A Tecpel SE-322 sound-level meter (Tecpel, Taipei, Taiwan) was used to measure sound pressure levels, pre-set to sample at $2 \mathrm{~s}$ intervals. This had auto-ranging measurement between 30 and 130 A-weighted decibels $(\mathrm{dB}(\mathrm{A}))$, an accuracy of $\pm 1.5 \mathrm{~dB}(\mathrm{~A})$, a capacity for 32000 data logs and an integrated LCD clock and data display.

\section{Procedure}

The observer, a medical student, qualified with a first class honours degree, ran six pilot cases in a urology theatre before data collection, receiving training and instruction from a human factors researcher in the practical aspects of data

\begin{tabular}{|c|c|}
\hline Level & Observed related effects \\
\hline 1 & Potentially distracting stimulus \\
\hline 2 & Non-case-related stimulus noticed by staff, not by sterile team \\
\hline 3 & Sterile team member momentarily distracted \\
\hline 4 & Sterile team member engages in distraction \\
\hline 5 & Sterile team member's primary task interrupted \\
\hline 6 & Sterile team momentarily distracted \\
\hline 7 & Sterile team engage in secondary tasks \\
\hline 8 & Sterile team's work interrupted-operation flow disrupted \\
\hline
\end{tabular}

collection. ${ }^{20}$ Training involved the reading of relevant literature, discussion of the method and the general principles of observational research, guidance and feedback during piloting.

During data collection, the observer was present in the capacity of a researcher within a university-based clinical safety research unit. During data collection, the observer positioned themself away from the operating table, ensuring an optimum viewing position, with each member of the sterile surgical team and all theatre doors in view; the observer's position once established was static. The observer positioned the sound meter beside them and directed it towards the operating table.

\section{Data collation and analysis}

We tallied observed events of distraction or interruption to form a total for each case. Similarly, we tallied the ordinal ratings attached to each distraction or interruption for each case to form a total. We also totalled the duration of interruption recorded to obtain a measure of interruption duration per case. To remove the bias of operation duration from the data we divided the totalled events by operation duration. We also obtained a percentage of interruption duration per case.

\section{RESULTS}

\section{Operations}

The 30 operations comprised the following: 2 circumcisions; 1 circumcision and vasectomy; I ligation of varicocoele; 1 scrotal exploration; 4 rigid investigative cystoscopies; 2 semi-rigid investigative cystoscopies; l semi-rigid cystoscopy with pyelography; 1 laser lithotripsy and stent removal; 1 stricture division; 4 transurethral resections of prostate; 2 transurethral resections of prostate and laser lithotripsy; 1 transurethral electrovaporisation of prostate; 1 bladder tumour excision; 1 bladder tumour biopsy and cystodiathermy; 1 ureteroscopy and laser lithotripsy; l ureteroscopy and tumour excision; 1 ureteroscopy and stent placement; I ureteroscopy and stent replacement; 1 ureteroscopy with lithotripsy and stent placement; 1 ureteroscopy and stent removal; and 1 ureteroscopy and ultrasonic lithotripsy.

\section{Operation duration}

Operation duration ranged from 7.43 to $312.73 \mathrm{~min}$, for the period from starting sterility to the end of the surgical operation. The mean operation duration was 52.35 (SE 10.70) $\mathrm{min}$.

\section{Observations}

Table 2 shows the summary statistics of observed events. The total of distraction or interruption events observed per case ranged from 1 to 89 , with a mean of 20.47 . The rate of events observed per minute ranged from 0.11 to 0.82 , with a mean of 0.45 events/min. The ordinal rating tally for each case ranged from 8 to 266. Cumulative work interruption as a percentage of the operation duration ranged from $0.41 \%$ to $50.17 \%$, with a mean of $13.05 \%$, an average of 5.66 min interruption per operation. Movement through the operating theatre was very frequent, with 1543 door-openings, a mean rate of 1.08/min for the whole sample.

Table 3 shows the data from the whole 30 -case sample for totalled distraction or interruption events observed, totalled ordinal ratings attached to them and their ratio, and work interruption duration, according to source category. The most frequent sources of distraction or interruption were conversations, work environment problems, telephone calls and equipment. The least frequent sources of distraction or interruption were movement in front of video monitors and bleepers. The categories with the highest ratings were conversations, equipment problems, work environment and telephone calls. Those 
Table 2 Summary statistics of observed events and interruption duration from the entire 30case sample

\begin{tabular}{llllll}
\hline & $\begin{array}{l}\text { Tally of events } \\
\text { per case }\end{array}$ & Events per minute & $\begin{array}{l}\text { Tally of ratings } \\
\text { per case }\end{array}$ & $\begin{array}{l}\text { Interruption } \\
\text { duration } \\
\text { per case (min) }\end{array}$ & $\begin{array}{l}\text { Interruption } \\
\text { duration }(\%) *\end{array}$ \\
\hline Mean & 20.47 & 0.45 & 71.90 & 5.66 & 13.05 \\
Maximum & 89.00 & 0.82 & 266.00 & 19.43 & 50.17 \\
Minimum & 1.00 & 0.11 & 8.00 & 0.10 & 0.41 \\
\hline
\end{tabular}

*Interruption duration as a percentage of case duration.

associated with the lowest ratings were movement in front of monitors and bleepers. Most work interruption was derived from conversations, equipment and procedural problems. Table 4 shows examples of the equipment, procedure and work environment.

\section{Noise measurement}

Each operation had a mean, maximum and minimum noise level. Mean noise levels ranged from a minimum of $51.14 \mathrm{~dB}(\mathrm{~A})$ to a maximum of $63.91 \mathrm{~dB}$, with an average of 56.92 (SE 0.58) dB. The average minimum noise level for an operation was 46.90 (SE 0.53) dB, and the average maximum noise level for an operation was 80.28 (SE 0.91) dB. The absolute minimum level recorded from the entire sample was $37.40 \mathrm{~dB}$ and the absolute maximum was $92.60 \mathrm{~dB}$.

\section{DISCUSSION}

In this study, an observer recorded distraction and interruption to the sterile surgical team in urological surgery. The sample was modest but sufficient to be representative of the operating theatre observed for the 2-month period of observation and that particular type of surgery. The results may not be indicative of other specialities or of the same type of surgery in other operating theatres. For this sample, the overall results showed a high frequency of distraction and interruption collectively amounting to notable work interference, determined by the level of sterile-team involvement and reflected by the high frequency of operating theatre door opening recorded.

The measures used, particularly the rating related to team involvement, must be scrutinised in terms of their validity and sensitivity. Research to date has shown reasonably high interrater reliability for both identifying distracting events in the operating theatre and rating them using this method. ${ }^{20}$ However, it is important to acknowledge that the measurement scale demands scrutiny, though we argue it is a logical one, and essentially serves its intended purpose in assigning some weight to relevant events. A simple tally of observed distraction and interruption events is useful in itself, but it does not show anything about the effect on the sterile team, whereas the scale accounts for team involvement. We attempt to show that some

Table 3 Totalled events observed and their ratings, and interruption duration associated with each source category

\begin{tabular}{lllll}
\hline Source & $\begin{array}{l}\text { Tally of } \\
\text { events (a) }\end{array}$ & $\begin{array}{l}\text { Tally of } \\
\text { event ratings } \\
\text { (b) }\end{array}$ & $\begin{array}{l}\text { Ratio of } \\
\mathbf{a} \text { to b }\end{array}$ & $\begin{array}{l}\text { Interruption } \\
\text { duration }\end{array}$ \\
\hline $\begin{array}{l}\text { Conversation } \\
\text { Phone }\end{array}$ & 198 & 902 & 4.55 & 100.62 \\
Bleeper & 130 & 283 & 2.17 & 4.05 \\
Equipment & 26 & 40 & 1.53 & 1.30 \\
Procedure & 58 & 376 & 6.48 & 35.48 \\
Environment & 163 & 195 & 5.41 & 26.73 \\
Monitor & 3 & 351 & 2.15 & 1.53 \\
& & 10 & 3.33 & 0.13 \\
\hline
\end{tabular}

sources of distraction may be frequent but not so disruptive, whereas others may be less frequent but more disruptive in relation to the team.

The measures, of course, depend on the observer's capacity to interpret events and this may vary from person to person, which is a potential weakness of the method. Observers may be biased in identifying some distractions rather than others. We need research to test explicitly whether observer characteristics confound the data and compromise the measures. Indeed, there are many issues to address with these and other observational measures for the surgical domain. We might further test their validity, perhaps in parallel with subjective measures from operating theatre personnel obtained postoperatively. We may also improve on the scale used here by reducing scale points. There may be other means by which to measure the severity of such events or their effects. Clearly, the object of analysis and the form of ratings of events could vary in different ways, and this is a matter for further research in relation to different research aims. For example, the object of analysis might relate to the operating surgeon or scrub nurse alone and the rating of distraction severity would demand a different scale, or even a completely different form of measurement. We might also revise categorisations to either separate sources or combine various sources of distraction in one or more categories, depending on the purpose of the further study.

Our results showed that frequency, rating tally and duration of work interruption varied according to source category. A closer analysis of these data may reveal some of the more disruptive interactions in the operating theatre (table 3 ). For instance, telephone calls and bleepers were highly frequent but had little observed effect on the sterile team and did not interrupt much work, as these were dealt with by other operating theatre personnel. In contrast, equipment-related problems were less frequent, but were associated with a higher rating, and accounted for over $30 \mathrm{~min}$ of interruption duration in the sample. Case-irrelevant communication was both frequent and associated with a high rating, accounting for 100 min of interruption in the sample. ${ }^{23}$ This supports previous claims that there may be "too much talk" in some operating theatres. ${ }^{24}$ Often, conversation was irrelevant to the case at hand, although relevant to other cases or hospital matters. Some talk was about procedure and equipment problems. Therefore, distractions of one type could have a persistent and prolonged affect, with a certain degree of interdependence or overlap among source categories. For instance, equipment problems involved more journeys outside the theatre for circulating nurses and increased work interruption for the sterile team waiting for resolutions for missing equipment or replacement of faulty equipment.

Noise went beyond acceptable ranges in some cases. For satisfactory speech-intelligibility, there should be a $10 \mathrm{~dB}$ difference between the ambient noise and speech noise at the position of the speaker (ISO 9921). Raised vocal effort reaches $66 \mathrm{~dB}$ (BS8233-CIBSE, 1994), so the noise level in theatre should be $<56 \mathrm{~dB}$. We found mean operative case noise 
Table 4 Examples of equipment, environment and procedure categories and their frequency

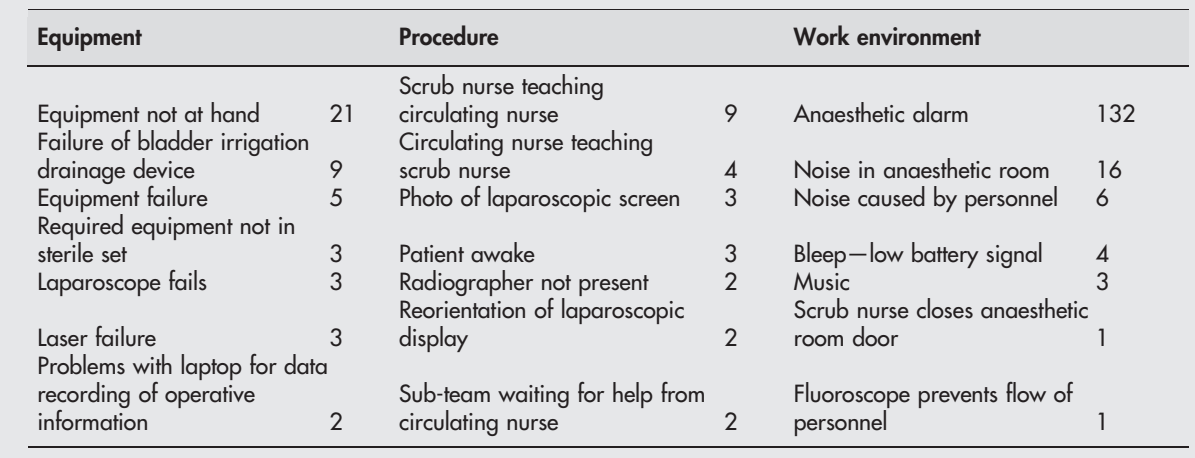

ranging between 51.14 and $63.91 \mathrm{~dB}$, and a mean case maximum of $80 \mathrm{db}$, so noise was acceptable in some cases and in some periods but not in others. This is consistent with previous studies that show high noise levels in the operating theatre. ${ }^{12} 2526$ High levels of background noise can have detrimental effects on communications and on cognition-for example, in terms of disruption to prospective memory ${ }^{27}$ and concentration. ${ }^{28}$

In aviation, it is recognised that distraction and the ineffective management of concurrent tasks may compromise safety. ${ }^{29}$ Work interrupted in the cockpit may lead pilots to rapidly forget their planned actions. ${ }^{30}$ Distractions in tandem with other system failures may lead to deviation in protocol or procedure and accidents. ${ }^{31}$ Operational procedures, such as "The 1981 Sterile Cockpit Rule", act to safely control the critical phases of flight. Rules and conditions for safe operating theatre work exist, but these mainly regard sterility and nursing protocol, such as swab and instrument counts, and anaesthetic protocol. Implicit localised or individualised rules regarding operational working practices also exist, but these will vary according to preferences from one surgeon, team or unit to another. There are no explicit rules for controlling work interference in surgery.

It is important to emphasise that aspects of distraction and work interruption are sometimes essential to work, because concurrent tasks are inherent to a professional's daily activity. ${ }^{21}$ Trade-offs in dealing with multiple tasks and multiple cases in this complex system are expected. However, it should not follow that we expect operating theatre personnel to deal with whatever variable work conditions they encounter; there is a limit to what individuals and teams may adapt to. More awareness of distraction and interruption may guide the improvement of surgical processes and standardise working conditions more uniformly. This is particularly important for addressing the continual change in surgical training, surgical procedure and new technology. Researchers need to evaluate team performance issues in surgery in general; these should include a focus on distraction and workload, and a pragmatic discussion of what constitutes multitasking, distraction, interruption and breaks. ${ }^{32}$

There was no attempt to relate the measures reported to patient care directly; for this we would need a much larger sample. Even with a larger sample we might find that work interference alone does not necessarily predict rates of adverse events or near misses. However, we would predict that work interference covaries with other factors such as individual performance levels and patient status, and together these may form the principal components that predict risks to patient care. The ability to distinguish between operations associated with high versus low levels of interference would clearly be helpful for improving the various aspects of performance and safety in surgery. However, there are statistical challenges in achieving a single score that represents the overall level of work interference.

These type of observational measures might confirm and correlate with data from critical incident reporting which clearly show that equipment and communications, for example, may often pose risks to patient care. Observational measures in turn may inform operating theatre personnel of the broader aspects of their system of work, the origin of distraction and potential effects. They may be useful in team debriefing and help in identifying problems unique to specific surgical specialities, surgical teams and operating theatres. Observational measures of various types may help in developing safe working parameters and serve to monitor working conditions once those parameters are established. Greater predictability and standardisation of working conditions could reduce workload and stress for surgeons ${ }^{33}$ and other operating theatre professionals in surgery, and ultimately enhance safety in surgery toward high-reliability.

\section{ACKNOWLEDGEMENTS}

We thank the Engineering and Physical Sciences Research Council, Swindon, UK (http://www.epsrc.ac.uk/default.htm) and The Health Foundation, London, UK (http://www.health.org.uk/).

\section{Authors' affiliations \\ A N Healey, C P Primus, M Koutantii, Imperial College, London, UK \\ Competing interests: None declared.}

\section{REFERENCES}

1 Etchells $E, O^{\prime}$ Neil C, Bernstein M. Patient safety in surgery: error detection and prevention. World J Surg 2003;27:936-42.

2 Calland J, Guerlain S, Adams R, et al. A systems approach to surgical safety. Surg Endosc 2002;16:1005-14.

3 Vincent C, Moorthy K, Sarker SK, et al. Systems approach to surgical quality and safety: from concepts to measurements Ann Surg 2004;239:475-82.

4 Chilton C. Patient safety and surgery. BJU Int 2004;4:463-4.

5 Weinger MB, Englund CE. Ergonomic and human factors affecting anesthetic vigilance and monitoring performance in the operating room environment. Anesthesiology 1990;73:995-1021.

6 Brennan TA, Leape LL, Laird NM, et al. Incidence of adverse events and negligence in hospitalized patients. Results of the Harvard Medical Practice Study I. N Eng J Med 1991;324:370-6.

7 Coxon JP, Pattison, SH, Parks JW, et al. Reducing human error in urology: lessons from aviation. BJU Int 2003;91:1.

8 Wilson JR. Fundamentals of ergonomics in theory and practice. Appl Ergon 2000;31:557-67.

9 Reason J. Human error: models and management. BMJ 2000;320:768-70.

10 National Patient Safety Agency UK. Quarterly National Reporting and Learning System data summary-Summer 2006. http://www.npsa.nhs.uk/site/media/ documents/1847_FINAL.APPENDIX.PSO_QTRLY.pdf (accessed 23 February 2007). 
11 Hughes RH. 1000 anaesthetic incidents: experience to date. Anaesthesia 2003;58:856-63.

12 Rogers SO, Gawande AA, Kwaan M, et al. Analysis of surgical errors in closed malpractice claims at 4 liability insurers. Surgery 2006;140:25-33.

13 Reason J. Human error: models and management. BMJ 2000;320:768-70.

14 Reason J. Beyond the organisational accident: the need for "error wisdom" on the frontline. Qual Saf Health Care 2004;13:ii28-33.

15 Carthey J. The role of structured observational research in health care. Qual Saf Health Care 2003;12(Suppl 2):ii13-6.

16 Thomas EJ, Sexton JB, Helmreich RL. Translating teamwork behaviours from aviation to healthcare: development of behavioural markers for neonatal resuscitation. Qual Saf Health Care 2004;13:i57-64.

17 Singh H, Petersen LA, Thomas EJ. Understanding diagnostic errors in medicine: a lesson from aviation. Qual Saf Health Care 2006;15:159-64.

18 Carthey J, de Leval MR, Reason JT. The human factor in cardiac surgery: errors and near misses in a high technology medical domain. Ann Thorac Surg $2001 ; 72: 300-5$

19 Catchpole KR, Giddings AE, de Leval MR, et al. Identification of systems failures in successful paediatric cardiac surgery. Ergonomics 2006:49:5-6, 567-88.

20 Healey AN, Sevdalis N, Vincent CA. Measuring intra-operative interference from distraction and interruption in the operating theatre. Ergononomics: special issue on patient safety 2006;49:589-604

21 Chisholm CD, Collison EK, Nelson DR, et al. Emergency department workplace interruptions: are emergency physicians 'interrupt-driven' and 'multitasking'? Acad Emerg Med 2000;7:1239-43.

22 Healey AN, Undre S, Vincent CA. Developing observational measures of performance in surgical teams. Qual Saf Health Care 2004;13(Suppl 1):i33-40.
23 Hodge B, Thompson JF. Noise pollution in the operating theatre. Lancet 1990;335:891-4.

24 Mahawar KK. Too much talk in theatre. Lancet 2003;361:9368, 1570-62.

25 Shapiro RA, Berland T. Noise in the operating room. N Eng J Med 1972;287:1236-8.

26 Moorthy VS, Malhotra SK, Bala I, et al. Detrimental effects of noise on anaesthetists. Can J Anaesth 1995;42:608-11.

27 Einstein GO, McDaniel MA, Williford CL, et al. Forgetting of intentions in demanding situations is rapid. J Exp Psychol Appl 2003;9:147-62.

28 Banbury SP, Berry DC. Office noise and employee concentration: identifying causes of disruption and potential improvements. Ergonomics 2005;48:25-37.

29 Dismukes RK, Loukopoulos LD, Jobe KK. The challenges of managing concurrent and deferred tasks. In: Jensen R, ed. Proceedings of the 11th International Symposium on Aviation Psychology. Columbus, $\mathrm{OH}$ : Ohio State University, 2001.

30 Loukopoulos LD, Dismukes RK, Barshi I. Cockpit interruptions and interferences: a line observation study. In: Jensen R, ed. Proceedings of the 11 th International Symposium on Aviation Psychology. Columbus, $\mathrm{OH}$ : Ohio State University, 2001.

31 Latorella KA. Investigating interruptions: implications for flightdeck performance, [PhD thesis]. Buffalo, NY: State University of New York. http:// www.interruptions.net/literature/Latorella-NASA-99-tm209707.pdf (accessed 23 February 2007)

32 Jett QR, George JM. Work interrupted. A closer-look at the role of interruptions in organisational life. Acad Manage 2003;28:494-508.

33 Wetzel CM, Kneebone RL, Woloshynowych M, et al. The effects of stress on surgical performance. Am J Surg 2006;191:5-10.

\section{$\mathrm{ECHO}$}

\section{Informed consent continues to baffle}

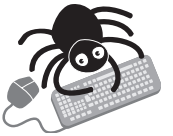

Please visit the Quality and Safety in Health Care website [www. qshc.com] for a link to the full text of this article. small UK study has suggested that factors other than adequate cognitive function
determine patients' understanding in the process of informed consent. Just how to obtain
truly informed consent remains elusive.

The prospective survey of consecutive outpatients undergoing endoscopy showed that all those with a high degree of understanding of the procedure had normal cognitive function (Mini Mental State Examination score $>24$ ), but so did $78 \%$ of those with low understanding, leaving just 22\% with low understanding and low cognitive function. Conversely, half of those patients with no understanding and $83 \%$ with low understanding had normal cognitive function. Among the 100 patients studied, 36 had low understanding and eight of these had subnormal cognitive function. Between 92 and 98 patients reported having had written or oral information about the procedure. The mean age of the cohort was 56 (median 52) years.

All patients were interviewed before endoscopy, immediately after giving consent, to gauge their understanding of the reasons for the procedure, its risks, what the procedure entailed, and aftercare. All outpatients are sent a written leaflet on the procedure, based on current national guidelines, before attending for endoscopy.

Informed consent is often difficult to satisfy fully because of patients' poor understanding. The researchers wondered whether cognitive function might be implicated, having found earlier that up to a third of outpatients had poor understanding and recall of consent they had just given. The role of cognitive function in informed consent has not been studied in a clinical setting.

A Yeoman AD, et al. Postgraduate Medical Journal 2006;82:65-69. 